\title{
DETERMINANTS OF ECONOMIC DEVELOPMENT INCENTIVES OFFERED BY STATES: A TEST OF THE ARMS RACE HYPOTHESIS
}

\author{
Mark A. Jenn and Farrokh Nourzad*
}

\begin{abstract}
This paper tests the "arms race" hypothesis, which postulates that states tend to increase their incentive offerings to new firms if such incentive programs are in use in other states that are perceived to be direct competitors. Using a pooled time-series/cross-section sample of twelve states covering the period from 1969 through 1985 and a model that controls for the effects of various economic and political factors, we find strong support for the "arms race" hypothesis. This result is robust to the alternative specifications of the incentive offerings and different measures of the degree of competition among states.
\end{abstract}

\section{"Alabama declared war on North and South Carolina last spring. No} blood was shed, but a lot of money was.... "

(Browning and Cooper, 1993, p. Al)

\section{INTRODUCTION}

The war referred to in Browning and Cooper's quote was a battle for the location of the new Mercedes Benz plant in the Unites States. The weapons of choice were economic development incentive packages. Alabama won this war, but at what cost? According to Browning and Cooper (1993), the tax abatement incentives alone reportedly will cost Alabama over $\$ 300$ million. Infrastructure improvements, government-paid retraining and purchasing the plant's land for Mercedes were all part of the deal. It is evident that the costs to Alabama will be enormous and only time will tell whether the benefits will be large enough to cover these costs.

A cost-benefit analysis of this and other incentive battles is a worthy pursuit, but before any such analysis can take place, one question must be answered. Do incentive offerings by states actually affect the locational decisions of firms? Cooper and Ruffenbach (1993) report that Mercedes executives claimed the incentive packages offered to them were not a major factor in their decision. Likewise, according to Bartik et al. (1987), Saturn officials claimed that the in-

\footnotetext{
We wish to thank the editors and three anonymous referees of the Review for their insightful comments on an earlier draft of this paper. The usual disclaimer applies.

*Graduate student, Economics Department, Marquette University, and Associate Professor of Economics, Marquette University.
} 
centives offered to them during their locational decision process in the mid-1980s mattered little.

A sizable literature exists on this subject, but the findings are contradictory. They indicate that at best, the effect of such incentive packages is marginal, and at worst they are a waste of resources. Given the ambiguity concerning the usefulness of such incentive packages, the question arises as to why states continue to use these packages so heavily. Several factors have been identified as possible reasons: employment problems, political factors, and income problems, to name a few. One hypothesis that is prevalent throughout the literature, but that has been only casually investigated, is the "arms race" (1985) hypothesis. ${ }^{1}$ Peretz (1986), Grady (1987), and Rubin and Zorn (1985) all alude to such a hypothesis. Peretz (1986, p. 625) identifies an "arms race" model as one where "states and localities are forced into matching and/or beating incentives provided by other states and localities." Only Grady (1987) has attempted to quantitatively examine this hypothesis and has found some evidence supporting it. $^{2}$ However, his analysis is overly simplistic because it is based on correlation coefficients that do not control for other influences.

In this paper, we test the "arms race" hypothesis using a time-series/crosssectional sample of twelve states and a model that takes into account the effects of various economic and political factors. We find strong support for the "arms race" hypothesis, but we obtain mixed results concerning the effect of political and economic factors on state incentive offerings. These findings suggest that some mechanism, be it voluntary or governmental, must be found in order to reign in the excessive competition among states for industrial development. If this mechanism does not materialize, states will continue to increase incentive offerings and thus increase the costs of economic development to levels where the net benefits of such development programs may be negative.

The remainder of the paper is organized as follows. In section II, the relevant literature is reviewed. In section III, an econometric model of incentive offerings by states is specified and the data used in this study are described. In section IV the results of the empirical analysis are presented and discussed. In the final section, limitations of this analysis are identified and suggestions for further research are offered.

\section{PREVIOUS WORK}

The first question that needs to be addressed is whether or not incentive offerings have any meaningful effect on the location of industries in states. Incentive packages such as the one offered to Mercedes by Alabama are centered 
around state and local tax breaks and infrastructure improvements. The literature concerning the effect of state and local taxes on locational decisions yields contradictory results. Grady (1987), Rubin and Zorn (1985), and Litvak and Daniels (1983) all conclude that state and local tax levels matter little to firms making locational choices because those taxes constitute a negligible portion of overall business costs. Recently, however, Bartik (1985) and Walker and Greenstreet (1991) have shown that lower tax levels increase the probability of sites being chosen for plant location.

Bartik (1991), who provides an extensive review of the literature since 1979, finds that inter-area studies encompassing decisions among states report a small and negative effect on various measures of business activity due to taxes. The median elasticity of business growth with respect to taxes found in these studies is -0.15 ; an increase in taxes of 10 percent would decrease long-run business activity by 1.5 percent. Although the effect of tax level differentials increases as the size of area under investigation decreases, state economic development battles occur at the inter-area level. These findings suggest that state and local taxes may have an effect on business growth, albeit a small one.

As far as the effect of infrastructure improvements is concerned, the literature is just as contradictory. Bartik (1991) analyzed studies concentrating on the effect of state and local public service spending on business growth, including infrastructure expenditures. He reports that 60 percent of such studies find at least one positive and statistically significant estimate associated with the public spending variable. A major problem arose because only three of the fifty studies surveyed properly controlled for the increased taxation necessary to carry out increased spending on public goods. It follows that in the cases of both state and local taxes and public goods spending, their effects on business growth may be ambiguous.

These surveys, though, address only general state and local policies, and not specific targeted incentive offerings. This is also true of studies such as those by Ladd et al. (1993) and Case (1992) concerning test variants of the "arms race" hypothesis in terms of fiscal copycatting by neighboring states or counties. To identify whether or not specific incentive packages have positive effects, case study and survey methods have been used. As noted earlier, after GM's Saturn subsidiary chose to locate its manufacturing plant in Tennessee, executives claimed that the individual state's incentive offers were not the determining factor in their location decision. Bartik et al. (1987) analyze Saturn's decision in more depth. By calculating the costs per vehicle at each of the finalist sites based on labor costs, transport costs and tax levels, they found that the lowest cost location was the one chosen in Tennessee. In this analysis the incentive packages were intentionally omitted, and even with their omission the authors came to the same 
locational decision as did Saturn. Even though several states, such as Minnesota and New York, offered substantial subsidies, with Minnesota's reportedly in the area of $\$ 1.2$ billion, the decision of Saturn was not swayed.

Walker and Greenstreet (1991) use a survey approach to analyze this issue. By contacting the industrial planners of firms located in the Appalachian region, the authors identified those industries that had searched for a site location among alternative localities or different states. Of these searchers, in only 15 percent of the cases did the incentive offers prove decisive in location decision. When one takes into account that local searchers, those choosing between sites within a municipality, were also included in the survey, one comes to the conclusion that the number of regional searchers affected by incentives are in fact very small. As was seen in Bartik's (1991) analysis, local searchers are more influenced by such incentives than regional searchers.

The existing literature does little to clear the fog surrounding the usefulness of state incentive offerings. Nevertheless, state economic development agencies continue to widely use incentive offerings to attract firms. A question that arises concerns the reason why states continue to offer incentives, given the ambiguity surrounding their effectiveness. The reasons can be grouped into three general categories: economic, political and competitive. First, states may be attempting to alleviate economic shortcomings. Grady (1987) uses two measures of economic influence on development policy, unemployment and manufacturing employment. It is hypothesized that states with high levels of unemployment will attempt to entice firms to locate in their region in order to create new jobs and increase employment. Also, as Grady notes, most incentive packages are offered to manufacturing firms. Thus, the level of manufacturing employment in a state can affect the amount of incentives offered by that state. A third economic influence is the level of state income. In certain states unemployment may not be a severe problem, but the population's level of income may be. If a large number of jobs in a state are low-skill, low-wage jobs, the state may attempt to lure higher-paying industries with incentive packages.

The second category of influences on incentive offerings are political factors. Grady (1987) identifies interest group strength as one potential factor in development policy choices. States with strong business interest groups should be more inclined to offer incentives to businesses due to pressure by these groups. Another political factor is the pressure placed on elected officials. Therefore, it may also be the case that incentive offering levels are affected by whether or not an election is being held presently or in near future.

The third general category consists of competitive factors. Here is where the "arms race" hypothesis lies. The key to this hypothesis is the uncertainty concerning the effectiveness of incentive offerings, and the risk aversion of policy-makers 
who fear the possible adverse consequences associated with not offering development incentives. The "arms race" hypothesis is an outgrowth of Walker's (1969) policy diffusion theory, which postulates that states are more likely to enact new programs if such programs are in use in states that are perceived to be direct competitors. This competition then escalates, since states are unable to coordinate policy, in this case over the distribution of employment across states (Rubin and Zorn, 1985). Competition forces states to increase incentive offers to "neutralize offers by other states" (Peretz, 1986, p. 630). Incentive offerings then turn into "arms races" among states as each must combat packages available elsewhere by developing their own incentives for offers to new firms.

Only Grady (1987) has attempted to evaluate each category of influence quantitatively. His analysis, however, though is simplistic to a fault. In the case of economic factors, he calculates correlation coefficients between changes in weighted incentive scores and changes in manufacturing employment and relative unemployment. These coefficients do not control for influences of other factors occurring at the same time which may wash out the separate effects of unemployment and manufacturing employment changes.

In the case of interest group strength, Grady calculates correlation coefficients between changes in incentive scores and Morehouse's (1981) categorization of state interest group strength. Once again, he ignores other factors that might have a bearing on the development decision. Similarly, when Grady analyzes the "arms race" hypothesis, he uses a simple rank-order correlation. By identifying regional groupings, he calculates the rank-orders of the states within those groups according to their weighted incentive offerings and examines whether these rankings are stable over time. Grady finds that in most regions, the rankings changed much over time. He then concludes that since the rankings at the beginning of the period are quite different from those at the end of the sample period, the changes can be attributed to an incentive "arms race". Again, the major shortcoming in this analysis is the failure to observe the entire context of the policy-making process. Only after this is done can more concrete results be obtained. In the next section we specify a model that controls for important aspects of the decision-making environment.

\section{MODEL, DATA, AND VARIABLE CONSTRUCTION}

Based on the above discussion of the three categories of influences, we formulate the following multiple regression model, 


$$
\begin{aligned}
\text { OFFER }_{i t} & =\beta_{0}+\beta_{1} C_{C O M P_{j t}}+\beta_{2} U_{R_{i t}}+\beta_{3} E_{M P} P_{i t}+\beta_{4} I_{N C} C_{i t}+\beta_{5} E_{L E C T} i t \\
& +\beta_{6} L O B B Y_{i t}+\varepsilon_{i t}
\end{aligned}
$$

where OFFER is a measure of incentives offered by state $i$ in period $t$; COMP denotes the degree of competition between state $i$ and states $j \neq i$ for testing the "arms race" hypothesis; UR is the ith state unemployment rate; EMP represents manufacturing employment in each state; INC is a measure of income; ELECT and LOBBY represent political influences; and it is an error term.

Using pooled time-series and cross-sectional data, we estimate four versions of Equation (1) that differ with respect to the specification of the dependent variable, OFFER, and the "arms race" variable, COMP. In the first model, the dependent variable, denoted OFFER1, is the weighted sum of 17 incentives that each state has authorization to offer in each year of the sample period. The periodical Industrial Development and Site Location surveys state economic development agencies yearly and reports the incentives offered by each state. ${ }^{3}$ Although this is an extensive review of the incentive offerings in each state, Grady (1987) accurately points out that it does not distinguish between policies of differing levels of importance. In order to overcome this problem, we follow Grady and use a survey of industrial facility planners conducted by the Industrial Development Research Council in 1977. Planners selected the top 10 locational incentives out of the 57 listed in Industrial Development. Scores were then calculated for each incentive based on the number of planners who ranked them as important. Of the top 20 selected, 17 are used in the present study due to data availability. ${ }^{4}$ These incentives and their scores are presented in the appendix. For each state we constructed a score based on which of these 17 incentives it offered in a given year.

In our first model, the independent variable representing the degree of competition among the states, denoted COMP1, is specified as the weighted sum of the 17 development incentives in state i minus the average of the weighted sum of the same 17 incentives offered by all other states $j \neq i$. If the "arms race" hypothesis is to be supported by the data, the estimated coefficient on COMP1 should be negative and statistically significant; if a state has a score which is decreasing in relation to its place among its competitors, COMP1 will decrease. If the determination of incentive offerings is based on the competition among states, a negative value of COMP1 should result in a positive change in incentive score as states attempt to catch up to their competitors.

In our second version of Equation (1), the dependent variable, OFFER2, is the simple sum of the 17 incentives mentioned above. This means that all incentives are assigned a weight of one, regardless of their relative importance to economic development. We also specify our measure of the degree of competition among the states, which we designate as COMP2, as the simple sum of the 17 
development incentives offered by state $i$ in year $t$ minus the average of the unweighted sum of the incentives offered by states $j \neq i$ in that year. The motivation behind this specification of Equation (1) is to examine the sensitivity of the results to the particular weighting scheme used to construct OFFER $1 .^{5}$ Once again, a negative and statistically significant estimate for the coefficient of this variable would support the "arms race" hypothesis.

In each of the first two version of Equation (1), the regressor representing the "arms race" hypothesis (COMP1 and COMP2) equals the corresponding dependent variable (OFFER1 and OFFER2) less the average number of incentives offered by other states. Thus the incentive offering by each state appears on both sides of the regression equation. This can be troublesome as the resulting regressor can be correlated with the random error term, $\varepsilon$, rendering the estimates biased and inconsistent. While this is testable, we will estimate a version of Equation (1) in which the dependent variable is OFFER1 described earlier but the "arms race" independent variable is simply the average of the weighted sum of incentives offered by other states, which we denote COMP3. Note that, unlike COMP1 and COMP2, a positive and statistically significant estimate for the coefficient of COMP3 would be consistent with the "arms race" hypothesis; more incentive offerings by other states would prompt state i to increase its offerings.

Finally, in order to examine the "arms race" hypothesis in terms of a specific type of development incentive, our fourth version of Equation (1) uses as the dependent variable, OFFER4, the weighted scores of nine tax incentives authorized by each of the twelve states in our sample in each year of the sample period. ${ }^{6}$ In this case, for the "arms race" independent variable we use the one-year lagged value of the average of the weighted sum of tax incentives offered by the other states, COMP4. ${ }^{7}$ As in the case of COMP3, the "arms race" hypothesis is supported if the estimated coefficient associated with COMP4 is positive and statistically significantly different from zero.

The other explanatory variables in Equation (1) are common to all four versions of this equation. The UR variable is the state unemployment rate taken from the Statistical Abstract of the United States. The sign of the coefficient on UR should be positive. As states encounter unemployment problems, they are compelled to increase incentive offerings to bring in new jobs.

EMP is the level of manufacturing employment in each state and is taken from the REIS Data Tape (1991). The sign of the coefficient on EMP is expected to be negative; a decrease in manufacturing employment is expected to cause an increase in development incentive offerings.

INC is real personal income by state, again taken from the REIS Data Tape. This variable is also expected to have a negative coefficient. This would indicate increases in incentive offerings due to income generation problems in a state. 
ELECT, which represents the political influences on policy decisions, is a dummy variable that equals one in the years in which states elect a governor. Governor's elections were chosen over legislative elections due to the increased level of coverage and participation that accompanies gubernatorial elections as opposed to legislative elections that many times pass nearly unnoticed. The sign of the coefficient associated with this variable is expected to be positive as attempts to attract businesses are intensified in election years in order to gain votes.

For LOBBY, which represents the strength of interest groups within a state, we use the measure suggested by Morehouse (1981) to define a dummy variable. She has developed a categorization of interest group strength by state based on surveys of elected officials and lobbyists and levels of funding and membership. Although Morehouse defines three categories of strength, Strong, Moderate and Weak, all of the states in our sample fall into the Strong or Moderate categories. Therefore, one dummy variable is used to distinguish between these two categories. In constructing this variable, we choose the strong category as the base so that this variable is expected to have a negative coefficient; states with moderate business interest groups pressure officials less heavily into subsidizing business, while states with strong interest groups will be pressured more.

Our sample covers the years 1969 through 1985. The choice of the period was dictated by data availability especially concerning manufacturing employment and income. As far as the choice of states is concerned, Grady (1987), Rubin and Zorn (1986), Walker and Greenstreet (1991) and Waselenko (1981) note that firms' location decisions normally take place on an inter-regional basis in that they first choose a specific region that fits their needs and then choose between locations in that region. With this in mind, along with recently highly contested locational battles, we include twelve Southern and Border states in our sample. ${ }^{8}$ With 15 years and 12 states, we have 180 observations.

\section{FINDINGS}

Before estimating our empirical model, we subjected all non-binary variables to two transformations. First, in order to compress their variance and thus reduce the likelihood of heteroscedasticity and nonstationarity in variance, we expressed all variables but two in the logarithmic form. The two regressors COMP1 and COMP2 contain some negative values and therefore their logarithm could not be taken. Second, in order to insure non-spurious results, all of the non-binary variables are first-differenced so as to remove the unit root that may be present in the data. ${ }^{9}$ 
The first step in the estimation process is to determine whether a fixed-effect (covariance) or a random-effect (error-components) model is the proper specification using Hausman's (1978) test. For none of the four versions of Equation (1) was the Hausman test statistic, which follows the $\chi^{2}$ distribution with 5 degrees of freedom, significant at reasonable levels. This suggests that all four models should be estimated as a random-effect specification. Diagnostic tests indicated that every one of the models suffered from heteroscedasticity and autocorrelation. To correct for these problems, we estimated the four versions of Equation (1) using two-step Generalized Least Squares (GLS). The estimation results are reported in Table 1.

\section{TABLE 1}

Estimates of State Development Incentive Offerings ( $p$-values in parentheses)

\begin{tabular}{|c|c|c|c|c|}
\hline 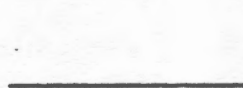 & $\begin{array}{c}\text { Model } 1 \\
\text { AlnOFFER } 1_{\text {it }}\end{array}$ & $\begin{array}{c}\text { Model } 2 \\
\text { AlnOFFER2 }{ }^{b}{ }^{b}\end{array}$ & $\begin{array}{c}\text { Model } 3 \\
\text { AlnOFFER } 3_{\mathrm{it}}{ }^{\mathrm{c}}\end{array}$ & $\begin{array}{c}\text { Model } 4 \\
\text { DInOFFER4it }\end{array}$ \\
\hline$\overline{\triangle C O M P 1_{j t}{ }^{e}}$ & $\begin{array}{r}-0.0005 \\
(0.0001)\end{array}$ & & & \\
\hline$\triangle C O M P 2_{j t}{ }^{f}$ & & $\begin{array}{r}-0.0329 \\
(0.0001)\end{array}$ & & \\
\hline$\triangle \mathrm{lnCOMP}{ }_{\mathrm{jt}}{ }^{\mathrm{g}}$ & & & $\begin{array}{r}0.4365 \\
(0.0001)\end{array}$ & \\
\hline$\Delta \operatorname{lnCOMP} 4_{j t-1}{ }^{h}$ & & & & $\begin{array}{r}1.9835 \\
(0.0001)\end{array}$ \\
\hline$\Delta \operatorname{lnINC} C_{i t}$ & $\begin{array}{r}-1.3024 \\
(0.0063)\end{array}$ & $\begin{array}{r}-0.7503 \\
(0.2086)\end{array}$ & $\begin{array}{r}-0.4173 \\
(0.2140)\end{array}$ & $\begin{array}{r}1.5893 \\
(0.1180)\end{array}$ \\
\hline$\Delta \mathrm{lnEMP}$ it & $\begin{array}{r}0.0679 \\
(0.7967)\end{array}$ & $\begin{array}{r}0.0152 \\
(0.9575)\end{array}$ & $\begin{array}{r}0.0352 \\
(0.8606)\end{array}$ & $\begin{array}{r}-2.4136 \\
(0.0001)\end{array}$ \\
\hline$\Delta \ln U_{R_{i t}}$ & $\begin{array}{r}-0.0724 \\
(0.0636)\end{array}$ & $\begin{array}{r}-0.1318 \\
(0.0008)\end{array}$ & $\begin{array}{r}-0.0423 \\
(0.1705)\end{array}$ & $\begin{array}{r}-0.5487 \\
(0.0001)\end{array}$ \\
\hline ELECT $_{\text {it }}$ & $\begin{array}{r}0.0167 \\
(0.1049)\end{array}$ & $\begin{array}{r}0.0011 \\
(0.9274)\end{array}$ & $\begin{array}{r}0.0041 \\
(0.6636)\end{array}$ & $\begin{array}{r}-0.1156 \\
(0.0001)\end{array}$ \\
\hline LOBBY $_{\text {it }}$ & $\begin{array}{r}-0.0383 \\
(0.0665)\end{array}$ & $\begin{array}{r}-0.0553 \\
(0.0034)\end{array}$ & $\begin{array}{r}-0.0154 \\
(0.2529)\end{array}$ & $\begin{array}{r}-0.1168 \\
(0.0001)\end{array}$ \\
\hline INTERCEPT & $\begin{array}{r}0.1587 \\
(0.0007)\end{array}$ & $\begin{array}{r}0.1235 \\
(0.0416)\end{array}$ & $\begin{array}{r}0.0588 \\
(0.0698)\end{array}$ & $\begin{array}{r}-0.1229 \\
(0.2134)\end{array}$ \\
\hline
\end{tabular}

OFFER $\mathrm{l}_{\text {it }}$ = weighted sum of 17 development incentives offered by state $\mathrm{i}$ in year $\mathrm{t}$

'OFFER2 $i_{i t}=$ simple sum of 17 development incentives offered by state $i$ in year $t$

${ }^{\mathrm{C}} \mathrm{OFFER}_{\mathrm{it}}$ = same as OFFER $1_{\mathrm{it}}$

${ }^{\text {dOFFER }} 4_{i t}=$ weighted sum of 9 types of tax incentives offered by state $i$ in year $t$

${ }^{\circ} \mathrm{COMPI}_{\mathrm{jt}} \quad=$ weighted sum of 17 development incentives offered by state $\mathrm{i}$ in year $\mathrm{t}$ minus average of the same 17 weighted incentives offered by states $j \neq i$ in year $t$

${ }^{\prime}{ }^{\prime} C O M P 2 j t=$ difference between simple sum of 17 development incentives offered by state $i$ in year $t$ and unweighted average of those offered by states $j \neq i$

${ }^{2} \mathrm{COMP}_{\mathrm{jt}}$ = weighted sum of 17 development incentives offered by states $j \neq i$ in year $t$

"COMP4 ${ }_{j t-1}=$ weighted sum of 9 types of tax incentives offered by states $j \neq i$ in the previous year 
Consider first the estimated coefficients on the variable representing the

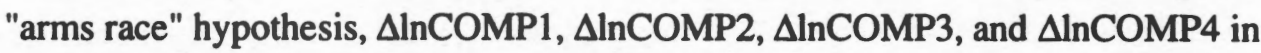
models 1 through 4, respectively. According to the results in Table 1, in models 1 and 2 the estimated coefficient on this variable are negative and highly significant, a result that supports the "arms race" hypothesis. ${ }^{10}$ In models 3 and 4 the estimated coefficients associated with this variable are positive and statistically significant. These results are also in support of the "arms race" hypothesis. ${ }^{11}$ These findings concerning the "arms race" hypothesis are robust to the specification of the dependent variable and the independent variable representing the degree of competition among states. It is important to note that the conclusion regarding the "arms race" hypothesis is reached while control is made for other economic and political influences.

Now consider the economic factors. The estimated coefficient on the log-difference of INC has the expected negative sign in models 1-3 but is statistically significant only in model 1 . In model 4 the estimated coefficient on income is positive but is not statistically significant at conventional levels. As far as the employment variable is concerned, its estimated coefficient is positive but is not statistically significantly different from zero in models $1-3$. In model 4 , on the other hand, this estimate has a negative sign and is highly significant, a result that is consistent with the notion that states use incentive packages as a countercyclical measure. The estimated coefficient on unemployment rate is negative in all four models and is statistically significant at the 10 percent level or better in models 1,2 , and 4 . Note, however, that the negative sign of this estimate is not consistent with our a priori expectation. The unexpected signs of the estimated coefficients on the employment and unemployment rate variables are likely to be due to the high correlation between these variables. Indeed, the correlation coefficient between $\ln U R$ and $\operatorname{lnEMP}$ is -0.70 , which is statistically significant $(t=13.08)$. Moreover, the correlation coefficient between $\triangle \ln U R$ versus $\triangle \operatorname{lnEMP}$ and $\triangle \ln I N C$ taken together equals 0.74 which is also statistically significant $(F=103.08)$. In spite of this, in all four models the estimated parameters associated with the three variables representing economic influences are jointly significant.

Turning to the political factors, we observe that the estimated coefficient on ELECT is positive but is not statistically significant in models $1-3$, whereas in model 4 this estimate is negative and statistically significant at high levels of confidence. ${ }^{12}$ The estimated coefficient on the special interest groups, LOBBY, has the expected negative sign and is statistically significant in all models but the third. In all four versions of Equation (1), the estimated coefficients associated with the two variables that control for political influences are jointly significant at high levels of confidence. These results point to the strength of non-economic factors in the determination of the level of business incentives offered by states. 
Although our sample consists of twelve southern and border states, many of the major incentive battles over the past 10 years have involved a handful of states. In both the cases of GM's Saturn plant decision and the Mercedes Benz plant decision five states, Kentucky, Tennessee, North Carolina, South Carolina, and Alabama, were either finalists or offered large packages. With this in mind, we re-estimated model 1 while restricting the sample to these five states. This regression was run without the LOBBY variable because all five states are ranked as strong in terms of interest group strength. The estimation results are reported below with p-values in parentheses,

\begin{tabular}{|c|c|c|c|}
\hline \multirow{2}{*}{$\triangle \operatorname{lnOFFER} \mathrm{it}_{\mathrm{it}}=$} & \multicolumn{3}{|c|}{$-0.1588-0.0009 \mathrm{COMP}_{\mathrm{jt}}+0.8177 \Delta \operatorname{lnEM} \mathrm{P}_{\mathrm{it}}+0.3467 \Delta \ln \mathrm{UR}_{\mathrm{it}}$} \\
\hline & $(0.0712)(0.0001)$ & $(0.0377)$ & \\
\hline & $\begin{array}{r}+1.5490 \Delta \\
(0.1021)\end{array}$ & $\begin{array}{r}+0.1222 \mathrm{E} \\
(0.0001)\end{array}$ & (2) \\
\hline
\end{tabular}

According to these results, all estimates are statistically significant at the 10 percent level or better. As in the case of the full-sample version of model 1, the estimated coefficients on the "arms race" and the election year variables also have the expected signs. As for the economic variables, unlike the results from the full sample, the unemployment variable has a parameter estimate that is of the expected positive sign and is statistically significant. The estimated coefficients on the other two economic variables, INC and EMP, while significant, have unexpected signs. In both cases this may be a result of reverse causation; higher incentive offerings can lead to higher levels of manufacturing employment and real personal income in these states.

\section{SUGGESTIONS FOR FURTHER RESEARCH}

The analysis presented in this paper can be improved in a number of ways. First, the economic factors can be extended to include other variables such as the number of firms a state attracts over the course of a year. Among other things, such a variable would account for increases in incentive offers due to success of previous incentive offerings. This in turn may allow the other economic variables to exhibit their true effects more clearly.

Second, more can be done to capture the effect of political factors. Since development policy takes place in a political atmosphere, these influences need to be better elaborated. A dummy variable representing interest group strength may not be enough. A more comprehensive measure needs to be used in order to better 
differentiate group strength among states. Also, a variable taking into account the composition of state legislatures, whether Democrat or Republican dominated, may offer insight.

Third, the dependent variable in each of the four models we estimated may be a less than optimal measure of the increasing use of incentives. By the end of the sample period considered in the present study, most states had made quite similar packages available to firms. Recently, the size of such packages has been under question so that a monetary measure of the magnitude of the offerings to firms may constitute a better indicator of incentive levels.

Finally, as can be seen from the restricted-sample regression results, there needs to be a better identification of regional competitors. This regression shows that in the Southern region there exists a subset of states that have competed even more strongly than other states in that region. The causes of this competitive edge need to be better investigated to identify whether these states are compelled to compete for different reasons than other southern states. Only after this question is answered can better modelling take place.

We found evidence suggesting that an incentive "arms race" may in fact be taking place. If this is true, the escalating level of incentives may be eroding the marginal benefits associated with offering such incentives. Some (e.g., Rubin and Zorn, 1985) have proposed some sort of control over the escalation of incentives for just such a reason. As states compete amongst themselves, the costs of economic development continue to grow, while the benefits remain essentially the same, and thus the net benefits continue to decrease. In any event, more research is necessary on all aspects of economic development policy, cost/benefit analysis, the effectiveness of incentives, and the motivations behind incentive offerings.

\section{ENDNOTES}

1. Other terms used in similar contexts are fiscal "copycatting," "spillovers," and "mimicking".

2. Variants of the "arms race" hypothesis have been tested in a more general context by Case et al. (1993) and Ladd (1992) among others.

3. This periodical was previously named Industrial Development and Industrial Development and Manufacture's Record.

4. The omitted incentives and their scores are industrial bond financing (191); wage incentive programs (44); and state programs promoting R\&D (20).

5. This was suggested by an anonymous referee of the Review.

6. These are items $1,3,4,5,7,9,10,11$, and 15 in the appendix. 
7. These last two versions of Equation (1) and the rationale for their use were suggested by another anonymous referee of the Review.

8. With a few exceptions, these states are the same as those used by Grady (1987) in his Southern Region comprised of Alabama, Arkansas, Florida, Georgia, Louisiana, Mississippi, North Carolina, South Carolina, Tennessee, Texas, and Virginia. The present study omits Arkansas due to data availability and Texas, due to its low level of incentive activity. We add Kentucky, Indiana and Ohio, due to their strong involvement in location competition.

9. Due to the small number of time periods, no formal test of stationarity such as the Dickey-Fuller unit root test was conducted. Instead, a visual inspection of the data plotted over time was performed that led us to believe that most variables are non-stationary.

10. In model 1 , we tested $\triangle \mathrm{COMP1}$ for endogeneity using Hausman's test. The test statistic, which has an asymptotic t-distribution, equaled -0.223 with a pvalue of 0.82 . Thus, we cannot reject the null hypothesis that in model 1 $\triangle \mathrm{COMPI}$ is exogenous.

11. Recall that because of the way COMP3 and COMP4 are specified, a positive sign on their coefficients would be consistent with the "arms race" hypothesis.

12. Note that in model 1 this estimate is significant at the $10.5 \%$ level.

\section{REFERENCES}

Bartik, Timothy. "Business Location Decisions in the United States: Estimates of the Effects of Unionization, Taxes, and Other Characteristics of States." Journal of Business and Economic Statistics 3 (1985): 14-22.

Who Benefits from State and Local Economic Development Policies? Kalamazoo, Michigan: W.E. Upjohn Institute for Employment Research, 1991.

Bartik, Timothy, Charles Becker, Steve Lake, and John Bush. "Saturn and State Economic Development." Forum For Applied Research and Public Policy. Spring 1987: 29-40.

Blair, John P., Rudy H. Fichtenbaum, and James A. Swaney. "The Market For Jobs: Locational Decision and the Competition for Economic Development." Urban Affairs Quarterly. 20 (1984): 64-77.

Browning, E. S., and Helene Cooper. "States' Bidding War Over Mercedes Plant Made for Costly Chase." The Wall Street Journal. November 24, 1993: A1A6. 
Case, Anne C., Harvey S. Rosen, and James R. Hines, Jr. "Budget Spillovers and Fiscal Policy Interdependence: Evidence From the States." Journal of Public Economics. 52 (1993): 285-307.

Conway, McKinley. "The Fifty Legislative Climates." Industrial Development and Site Location, Atlanta, Georgia: Conway Data, Inc., 1969-1985.

Cooper, Helene and Glenn Ruffenach. "Alabama's Winning of Mercedes Plant Will Be Costly, With Major Tax Breaks." The Wall Street Journal. September 30, 1993: A2.

Eisinger, Peter K. The Rise of the Entrepreneurial State: State and Local Economic Development Policy in the United States. Madison, Wisconsin: University of Wisconsin Press, 1988.

Hausman, Jerry A. "Specification Tests in Econometrics." Econometrica. 46 (1978): 1251-1271.

Helms, L. Jay. "The Effect of State and Local Taxes on Economic Growth: A Time Series Cross Section Approach." The Review of Economics and Statistics. 67 (1985): 574-582.

Industrial Development Research Council. The Industrial Facility Planner's View of Special Incentives. Atlanta, Georgia, 1977.

Grady, Dennis O. "State Economic Development Incentives: Why Do States Compete?" State and Local Government Review. 45 (1987): 86-94.

Ladd, Helen F. "Mimicking of Local Tax Burdens Among Neighboring Counties." Public Finance Quarterly. 20 (1992): 450-464.

Livak, Lawrence and Blenden Daniels. "Innovations in Development Finance." In Michael Barker, (ed.). Financing State and Local Economic Development, Durham, North Carolina: Duke University Press, 1983.

Lowery, David, and Virginia Gray. "Holding Back the Tide of Bad Economic Times: The Compensatory Impact of State Industrial Policy." Social Science Quarterly. 73 (1992): 483-495.

Morehouse, Sarah. State Politics, Parties and Policy. New York, New York: CBS Publishing, 1981.

Peretz, Paul. "The Market for Industry: Where Angels Fear to Tread?" Policy Studies Review. 5 (1986): 624-633.

Rubin, Barry M. and C. Kurt Zorn. "Sensible State and Local Economic Development." Public Administration Review. 45 (1985): 333-339.

Walker J.A. "The Diffusion of Innovations Among the American States." American Political Science Review. 63 (1969): 880-889.

Walker, Robert and David Greenstreet. "The Effect of Government Incentives and Assistance on Location and Job Growth." Regional Studies. 25 (1991): 1330. 
Wasylenko, Michael. "The Location of Firms: The Role of Taxes and Fiscal Incentives." In Robert Bahl (ed.). Urban Government Finance: Emerging Trends. Beverly Hills, California: Sage Publications, 1981.

Wasylenko, M., and T. McGuire. "Jobs and Taxes: The Effects of Business Climate on States' Employment Growth Rates." National Tax Journal. 38 (1985): 497-511. 


\section{APPENDIX: INCENTIVE OFFERINGS AND THE} CORRESPONDING SCORES

Incentive

1. Property tax exemption or moratorium on land, capital improvements

Score

2. State right-to-work law 207

3. Property tax exemption on manufacturing inventory

4. Corporate income tax exemption 199

5. Property tax exemption on equipment

6. Accelerated depreciation

7. State tax exemption-new equipment

8. State supported training

9. Property tax exemption-materials used in manufacturing

10. Inventory tax exemption-goods in transit

11. License or excise tax exemption

12. State supported recruiting, screening of industrial employees

13. Statewide uniform property tax law

14. Tax stabilization for specified industries

15. Tax exemption for research and development

16. State or local loans for plant construction

17. State incentives to establish plants in high unemployment areas 